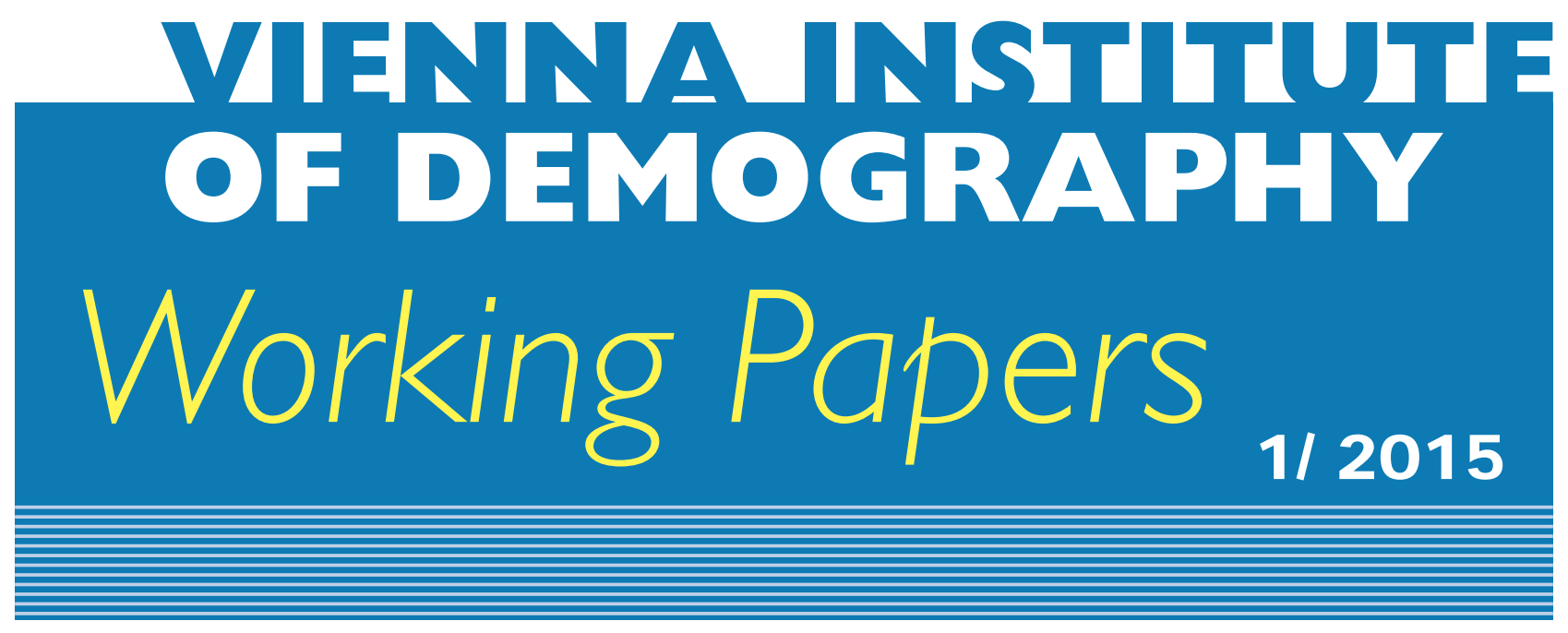

Isabella Buber-Ennser

\title{
Aspects of Gender $M$ ainstreaming of Family and Work in Austria
}

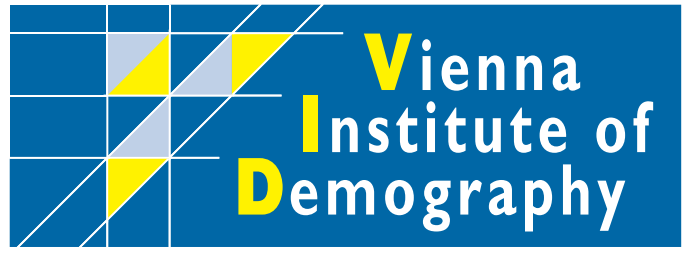

Vienna Institute of Demography Austrian Academy of Sciences

Wohllebengasse 12-14

A-I040Vienna $\cdot$ Austria

E-Mail:vid@oeaw.ac.at

Website: www.oeaw.ac.at/vid

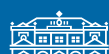

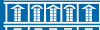

[囱面面回

OAW of Sciences 


\begin{abstract}
OECD regularly carries out surveys in its member states to assess their recent economic performance. For the preparation of the 2015 survey focusing on gender mainstreaming of family and work arrangements in challenging times, an OECD team conducted a "factfinding mission" at the Federal Chancellery in Vienna. The mission team approached several researchers and policy makers in order to discuss the recent situation in Austria. The team circulated a strategy note, including a detailed outline of the planned survey, aiming at stimulating scientific and policy-relevant exchanges. In order to discuss the outline of the mission document concerning fertility, migration and the triangular interaction between labour market participation, well-being and parenthood/fertility, I summarized insights from empirical research for Austria based a review of the existing literature. This summary was provided to the OECD team and constituted the major input for discussion.
\end{abstract}

\title{
Keywords
}

Gender policies, gender mainstreaming, Austria, OECD

\section{Author}

Isabella Buber-Ennser is researcher at the Wittgenstein Centre (IIASA, VID/ÖAW, WU), Vienna Institute of Demography/Austrian Academy of Sciences, Austria.

Email: isabella.buber@oeaw.ac.at

\section{Acknowledgements}

Thanks to Tomáš Sobotka for valuable comments. 


\title{
Aspects of Gender Mainstreaming of Family and Work in Austria
}

\author{
Isabella Buber-Ennser
}

\section{Introduction}

OECD regularly carries out surveys in its member states to assess their recent economic performance. A key dimension for economic growth and wellbeing is progress with gender equality. Austria has traditionally been characterised by a separate gender roles model, contributing to the well-being of children, dependent elderly and families in general, but reducing female labour force participation and confining women in special roles. Growing aspirations for a less gender-differentiated and more gender-balanced society have been identified as a key challenge in the 2013 OECD Economic Survey on Austria. Austrian authorities invited OECD to follow-up on this issue in the 2015 survey and to prepare a review of Austria's gender outcomes and gender policies in an international comparison.

For the preparation of this 2015 survey focusing on gender mainstreaming of family and work arrangements in challenging times, a "fact-finding mission" took place in Vienna on 1-5 December 2014 at the Federal Chancellery. The OECD mission team - headed by Andreas Wörgötter - approached researchers and policy makers in order to discuss the recent situation in Austria. The team circulated a strategy note, including a detailed outline of the planned survey, aiming at stimulating scientific and policy-relevant exchanges. Numerous issues have been listed in this note, capturing on the one hand gender balances in Austria and on the other a policy toolbox for gender mainstreaming.

In order to discuss the outline of the mission document concerning fertility, migration and the triangular interaction between (1) labour market participation, (2) well-being and (3) parenthood/fertility, the Vienna Institute of Demography (VID) of the Austrian Academy of Sciences was approached. Together with Tomáš Sobotka, we represented VID at the meeting and prepared insights from empirical research for Austria. This review on existing literature in the context of demography was provided to the OECD team and constituted the major input for discussion. The current paper presents a slightly modified version of the review. Parts of the slides presented at the meeting are included in this manuscript as figures.

\section{Enrolment in Childcare ${ }^{1}$}

\section{Key messages:}

- Enrolment at age 0-3 remains comparatively low, but it has been increasing rapidly after 2007, doubling in 2007-2013

\footnotetext{
${ }^{1}$ This chapter refers to the statements $28,33,70,71$ in the OECD strategy note.
} 
- Huge regional differences in enrolment and accessibility of full-day early childcare exist

Most recent available data on enrolment in childcare by age of the child have been published by the Austrian Institute for Family Studies (Dörfler, Blum, \& Kaindl, 2014). The report uses administrative data from Statistical offices and captures children in child care institutions and childminders for the years 2012/13 and 2010/11 respectively. ${ }^{2}$ Based on administrative data, Austria has a lower rate of enrolment in childcare for children below age 3 than France, Germany and Sweden. The enrolment amounted to 23.3\% in 2013 (see Figure 1) and has doubled during the last six years, from 11.8\% in 2007. Enrolment in Germany is currently about 30\%. In France and Sweden, every second child below age 3 is enrolled in external childcare. Childcare outside the family usually does not start before the child's first birthday, but at the age of 2 years, about 9 out of ten children are enrolled in external childcare in these two countries.

Figure 1: Enrolment in childcare 2012/13

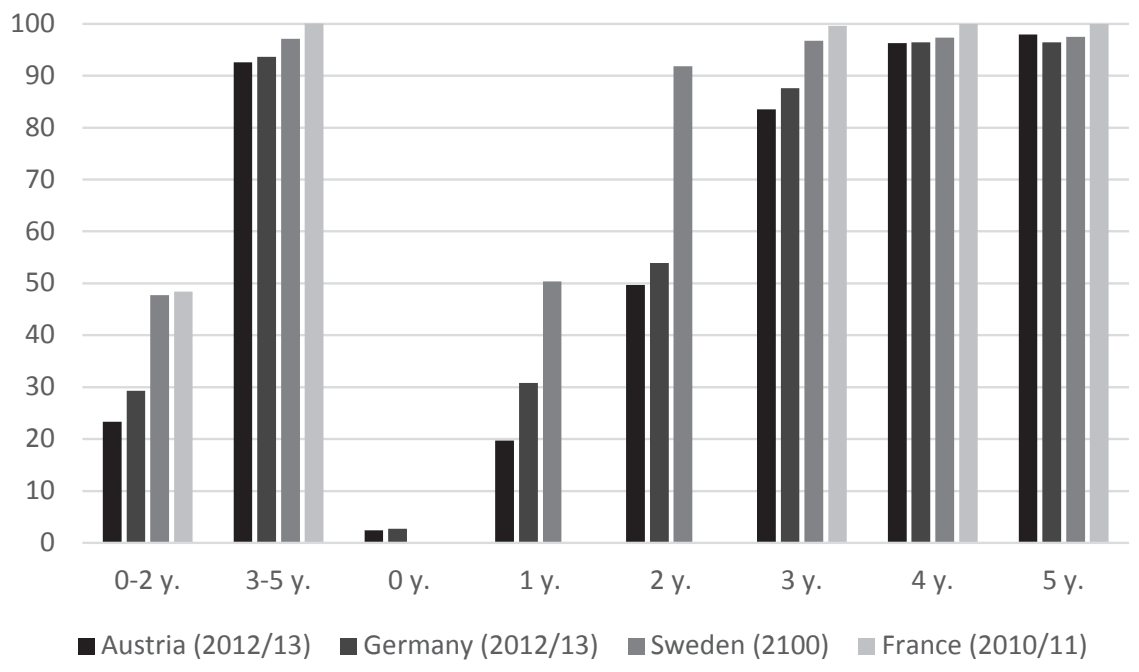

Source: Administrative data (AT, DE, SE); administrative data and EU-SILC (FR) Dörfler, Blum and Kaindl (2014)

Enrolment in childcare facilities for children below age 3 was clearly below the EU directive of 33\% in 2010. A specific feature of childcare facilities in Austria are large regional differences between provinces (Bundesländer) (Blum \& Kaindl, 2014), with the enrolment varying from 12\% in Styria to 40\% in Vienna in 2013 (see Figure 2 and Table 1). These differences also relate to opening hours (many facilities in Styria and Tyrol close as early as $2 \mathrm{pm}$ or earlier) and qualitative factors such as the ratio children to carers or the size of the groups. Parents often resort to relatives and, to a lesser degree, to home-based childminders (Blum \& Kaindl, 2014; Plantenga \& Remery, 2009).

\footnotetext{
${ }^{2}$ OECD data come from different sources, one of them being EU-SILC and that there is a drawback regarding data on children below age 3 , as in half of all countries captured by OECD data, numbers are low or too low to allow valid calculations of childcare enrolment for children below age 3 (Dörfler et al., 2014).
} 
Figure 2: Regional differences in enrolment in childcare of children below age 3, 2011/12, by districts

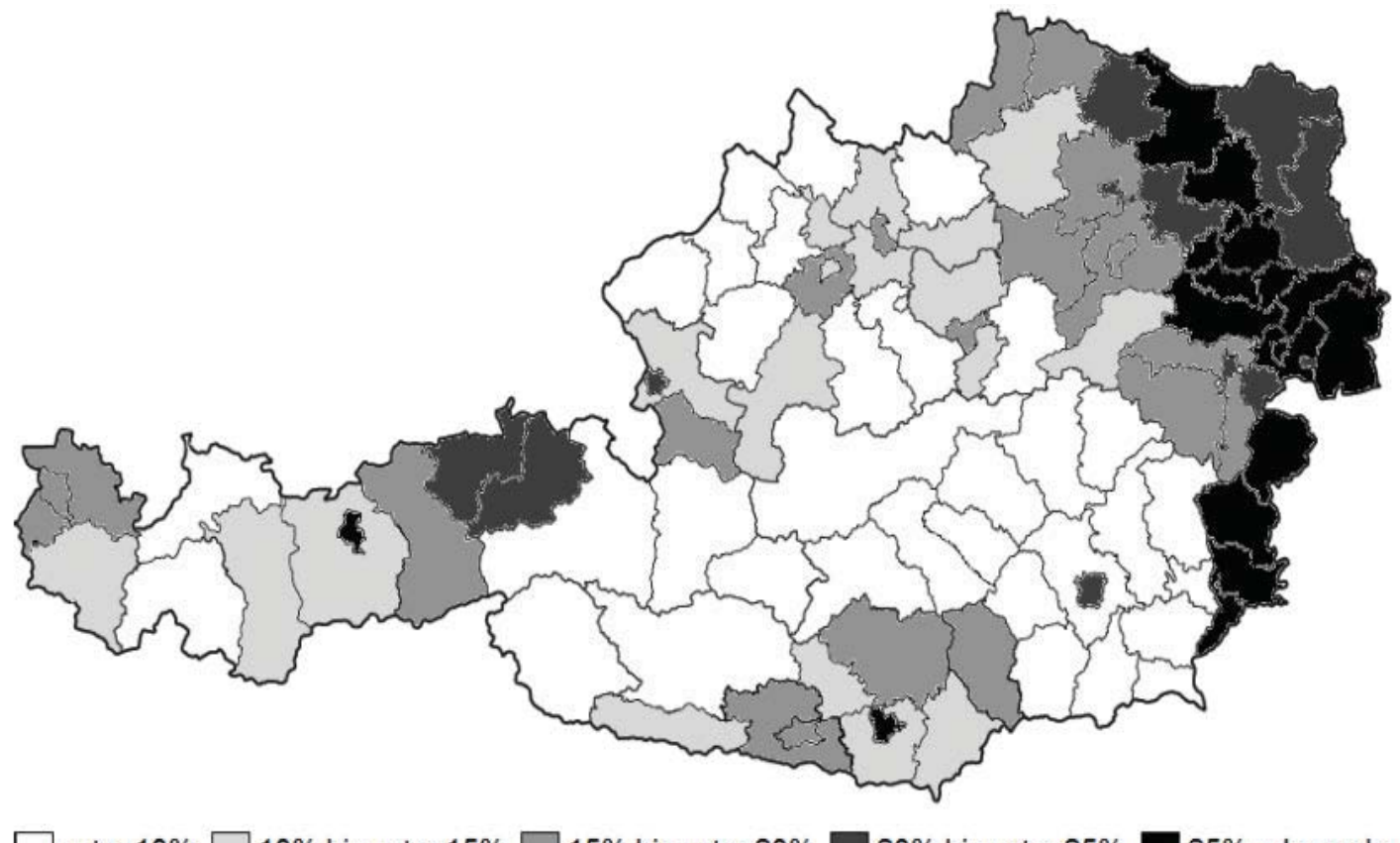

unter $10 \% \square 10 \%$ bis unter $15 \% \square 15 \%$ bis unter $20 \% \square 20 \%$ bis unter $25 \%$

$25 \%$ oder mehr

Source: Blum and Kaindl (2014)

Table 1: Regional differences in enrolment in childcare of children below age 3, 20072014, by federal States

\begin{tabular}{llll}
\hline Federal State & $2007 / 08$ & $2011 / 12$ & $2013 / 14$ \\
\hline Burgenland & $15.3 \%$ & $29.0 \%$ & $31.3 \%$ \\
Carinthia & $12.7 \%$ & $16.5 \%$ & $18.5 \%$ \\
Lower Austria & $8.7 \%$ & $21.2 \%$ & $22.3 \%$ \\
Upper Austria & $6.0 \%$ & $11.2 \%$ & $12.8 \%$ \\
Salzburg & $9.9 \%$ & $14.1 \%$ & $17.6 \%$ \\
Styria & $5.6 \%$ & $10.0 \%$ & $11.9 \%$ \\
Tyrol & $12.3 \%$ & $18.0 \%$ & $21.7 \%$ \\
Vorarlberg & $11.6 \%$ & $17.3 \%$ & $20.5 \%$ \\
Vienna & $23.1 \%$ & $33.2 \%$ & $40.3 \%$ \\
Austria & $\mathbf{1 1 . 8 \%}$ & $\mathbf{1 9 . 7 \%}$ & $\mathbf{2 3 . 0 \%}$ \\
\hline
\end{tabular}

Source: Statistics Austria 2008, 2012, 2014

Blum and Kaindl (2014)

Within the nine Austrian Federal states (Bundesländer) differences in legal arrangements regarding child-to-staff ratio are substantial (Blum \& Kaindl, 2014). Insight from a qualitative study revealed severe flaws in the quality of childcare. In regards to personal situation, child-to-staff ratio, training and working conditions of childminders, and age-limits for entering childcare facilities (Blum \& Kaindl, 2014). 


\section{Work Arrangements of Parents ${ }^{3}$}

\section{Key message: \\ - A combination of mothers' part-time labour participation and fathers' full-time employment has emerged as a new dominant model of parents' labour participation across all education groups}

A recent study examines work arrangements of parents with children below age six in Austria, based on Austrian microcensus data from 1980 to 2009 (Berghammer, 2014). A distinction is made between male breadwinner model, "modernized male breadwinner" model and dual breadwinner model. The "modernized male breadwinner" model refers to the situation where mothers work part-time, whereas their male partners continue with fulltime employment.

Over the period of almost 30 years, parents with various combinations of educational attainments opted more and more frequently for the modernized male breadwinner model in which women work part-time. The latter has become the most common arrangement among parents with pre-school children (Figure 3). The results are interpreted in the light of institutional and cultural factors, playing special attention to parental leave regulations, the availability of childcare places and attitudes towards mothers' employment. Berghammer remarks that it is a consequence of policies expanding parental leave and settling incentives for part-time work, as well as the insufficient availability of childcare places which make full-time work 'costly' and difficult to implement.

Approximately two-thirds of parents currently opt for the male breadwinner model when their child is below age three, with the remaining third balanced between modernized male breadwinner and dual earner breadwinner (Figure 3). This pattern is unique in Europe. The modernized male breadwinner model is prevailing when children are at preschool age or school age, too. Around a half of the parents can be characterised by the modernized male breadwinner model, regardless of whether their youngest child is 3-5, 6-9 or 10-14 years old (Klapfer, 2010).

\footnotetext{
${ }^{3}$ This chapter refers to the statements $28,33,70$ in the OECD strategy note.
} 
Figure 3: Work arrangements of couples with children below age 6, 1980-2002
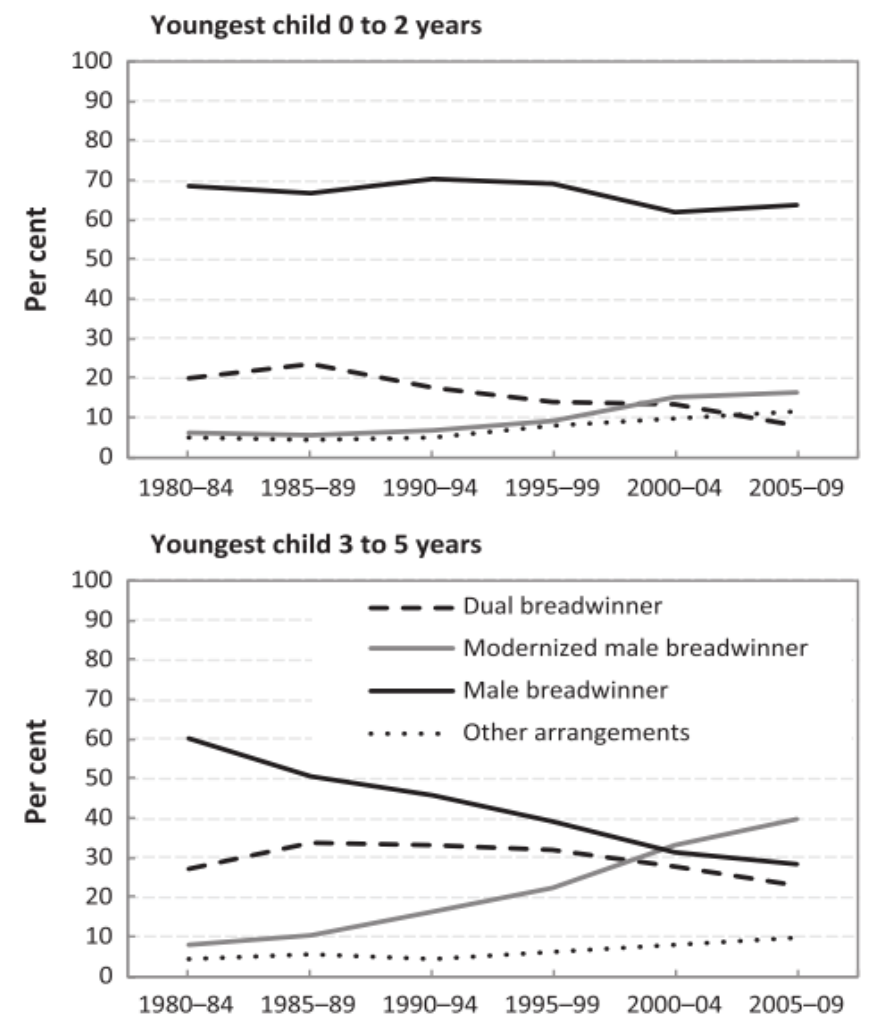

Source: Berghammer (2014)

Berghammer's study focuses on combined educational level of parents. The findings show converging trends between different educational groups. Couples with children below age of three whose mothers are highly educated increasingly turn away from the dual breadwinner model and, rather unexpectedly, choose the modernised breadwinner model (Figure 4). Asking if the male breadwinner model is returning, she concludes that this definitely applies to couples in which women are highly educated and have an infant. The result is rather unexpected given a seemingly universal trend towards higher gender equality and mothers’ rising labour market participation. 
Figure 4: Work arrangements of couples with youngest child 0 to 2 years
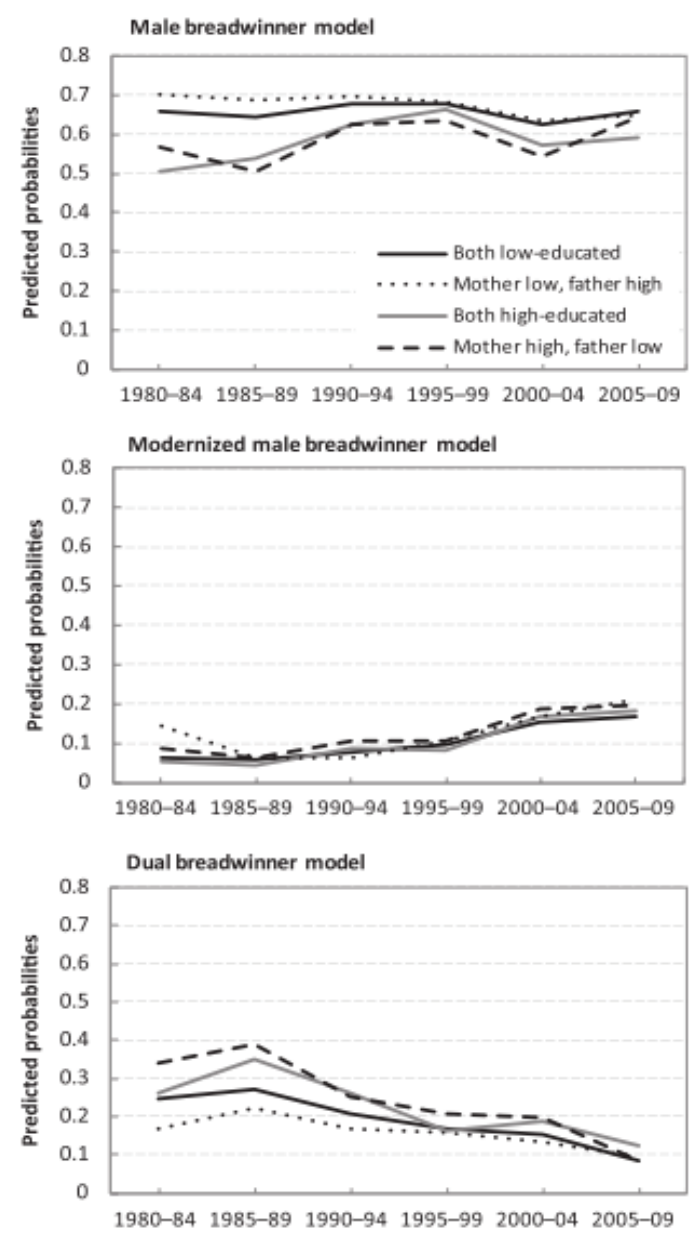

Source: Berghammer (2014)

Another important result of this study is that the educational effect has declined over time, that is, employment patterns between educational groups have converged. When the youngest child is less than three years old, highly educated mothers increasingly adapt to the behaviour of their low-educated peers in that they delay their return back to work (Figure 4). This development can most likely be explained by the repeated prolongation of parental leave during the observation period (1980-2009). By the time children are preschoolers, the shift from the dual breadwinner model is steeper among parents with a highly educated mother than among their lower-educated peers (Figure 5). The Austrian findings are surprising in view of the fact that results for Germany document a growing divide between mothers with different educational backgrounds (Konietzka \& Kreyenfeld, 2010). 
Figure 5: Work arrangements of couples with youngest child 3 to 5 years
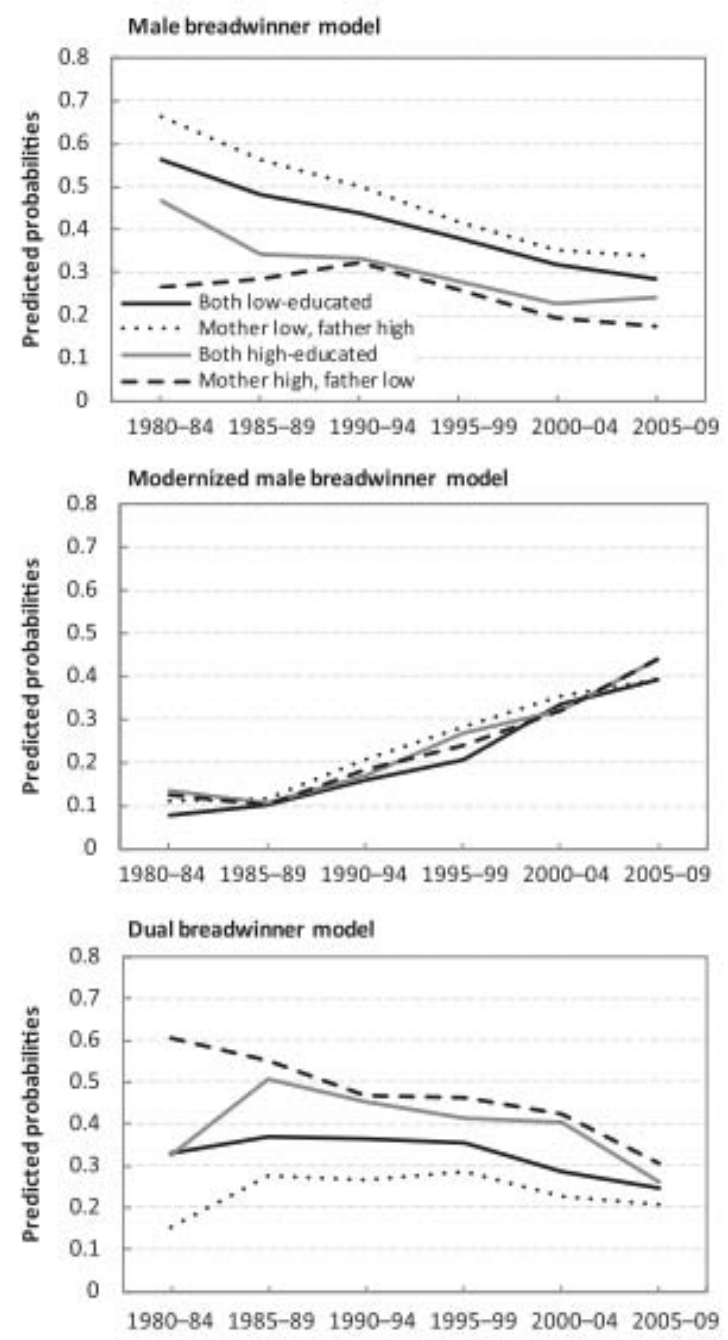

Source: Berghammer (2014)

\section{Fathers' Involvement in Childrearing ${ }^{4}$}

\section{Key message:}

- Austrians are particularly aware of fathers' presence and active role in childrearing

Attitudes towards the statements "A pre-school child suffers if his/her mother works" and "Children often suffer because their fathers concentrate too much on their work" have been analysed recently. Austrians are particularly aware of the importance of fathers' presence and their active role in raising children (Buber-Ennser \& Panova, 2014). For fathers'

\footnotetext{
${ }^{4}$ This chapter refers to the statement 44 in the OECD strategy note.
} 
concentration on work, agreement was highest in Austria, Hungary and Poland (80\%, 77\% and $73 \%$ respectively), and lowest in Australia, Romania and Norway (29\%, 41\% and 41\%) (Figure 6). In the remaining countries, agreement was between 53\% and 67\%. Agreement might be interpreted as an indicator for awareness of the importance of fathers' presence and their active role in childrearing, or, alternatively, as an awareness of fathers' too long work hours which prevents them from spending more time with their family. Gender differences are exceptionally large in Austria with men agreeing much more often than women that children suffer from fathers' concentration on work.

Figure 6: Attitudes towards fathers' concentration on work (in percent)

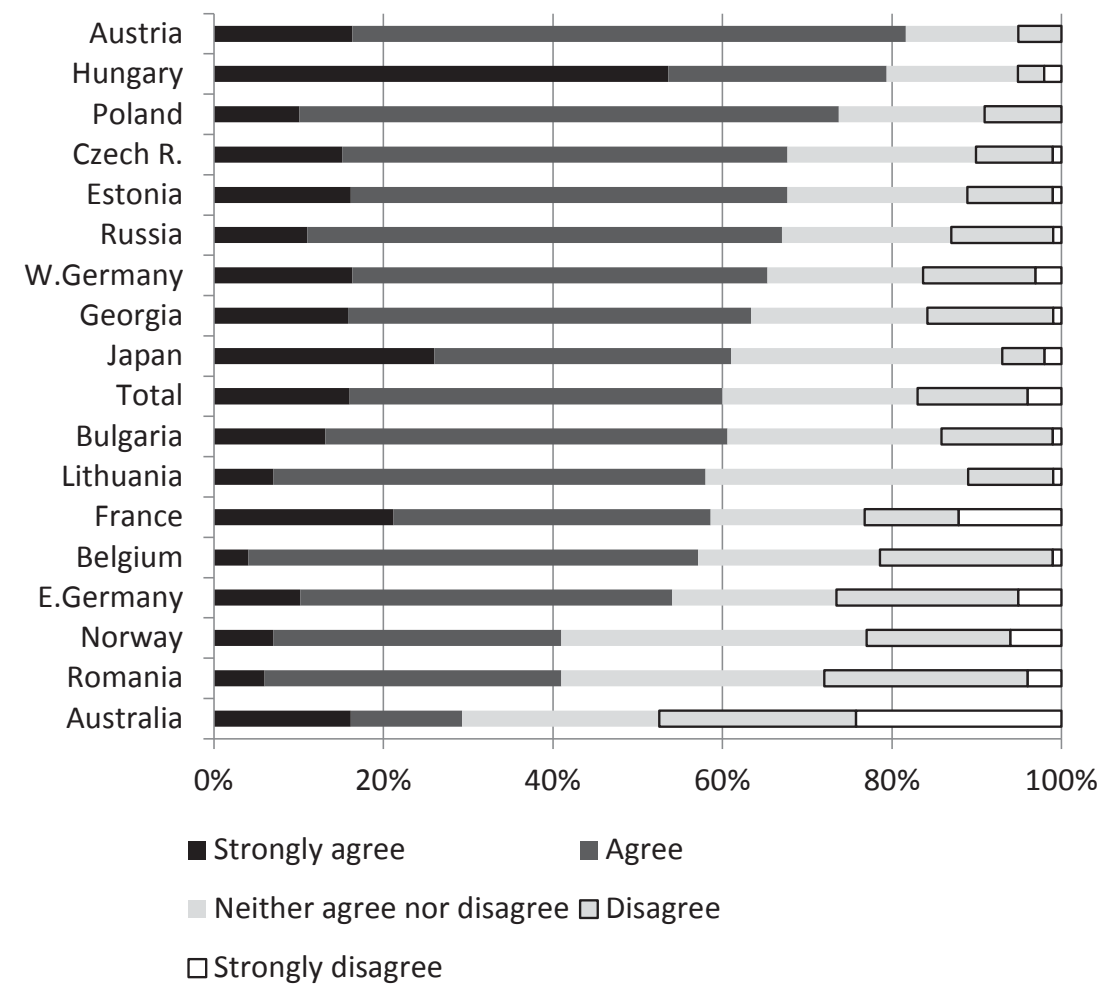

Source: Buber-Ennser and Panova (2014)

To add, a recent study found that employed full-time spend more time with their children. Based on time-use data (1992 and 2008/09) the study showed that the time devoted to child care has increased in Austria (as in many other western countries). In particular three groups, namely (1) fathers employed full-time who have non-employed partners, (2) housewives and (3) parents with medium education spend more time with their children in Austria (comparison 1992 and 2008/09) (Berghammer, 2013). 


\section{Attitudes towards Employment of Mothers with Pre-School Children ${ }^{5}$}

\section{Key message:}

- Regarding attitudes towards employment of mothers with pre-school children, Austria holds a medium position, with large differences between women and men

A ranking for attitudes towards employment of mothers with pre-school children across 14 European countries - among them ten located in central and eastern Europe, Australia and Japan-identifies three broad groups (Buber-Ennser \& Panova, 2014). (Figure 7):

Most traditional countries are Hungary, Georgia, Russia, Bulgaria, Poland and Lithuania. Australia, western Germany, Romania, France, Austria and the Czech Republic hold a medium position.

Belgium, eastern Germany, Japan, Estonia and Norway are the least traditional countries. Japan holds an intermediate position (liberal/medium position)

The gap in attitudes between men and women is largest in Austria and Norway and substantially large in western Germany. We might conclude that especially in Austria, western Germany and Norway men hold much more traditional views than women.

Attitudes vary by socio-demographic characteristics (gender, age, education, employment status or number of children). In Austria differences by education are very large. Further evidence is provided by Berghammer (2014) for the period 1988-2002 (age 18-54). An agreement with the view that preschool children suffer when mothers work decreased from $79 \%$ to $60 \%$ among the low educated and declined from $56 \%$ to $43 \%$ among the higher educated. The relative gap in attitudes by education has thus remained stable over time. To add, there is still reluctance towards the degree of employment in Austria. Part-time is regarded as the preferred way to combine family and work (Berghammer, 2014). In line, another study showed that in Austria a high proportion of persons considers it desirable that mothers do not participate in the labour force when children are at pre-school age (Wernhart \& Neuwirth, 2007).

\footnotetext{
${ }^{5}$ This chapter refers to the statement 48 in the OECD strategy note.
} 
Figure 7: Country typology based on attitudes towards „A pre-school child suffers if his/her mother works"(age 18-45)

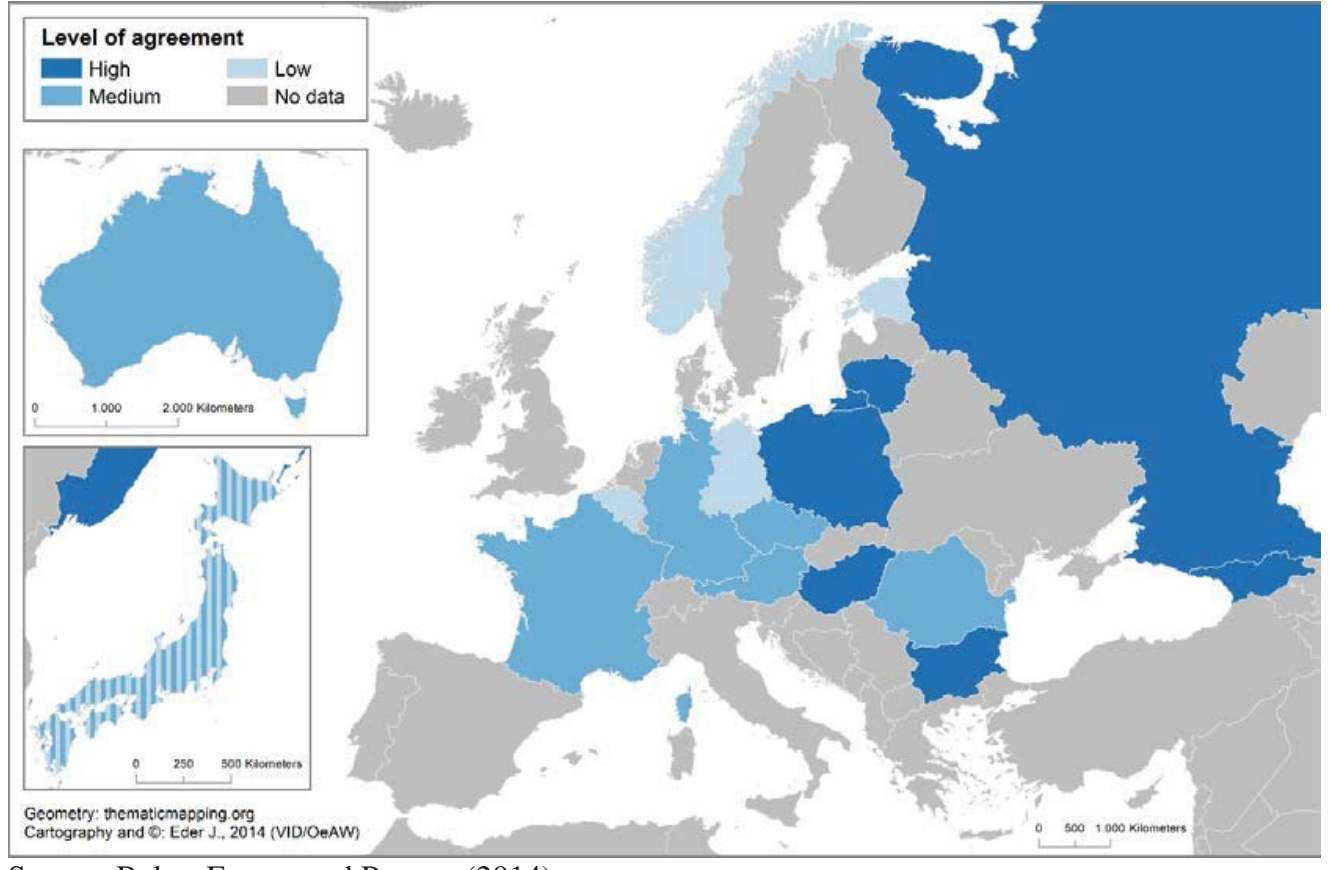

Source: Buber-Ennser and Panova (2014)

\section{Does Gender Equality Matter for Fertility? ${ }^{6}$}

\section{Key message:}

- Only if the actual gender differences are also perceived as gender inequalities (i.e., as being unfair or unjust), depressing effects on fertility may be expected.

Very low fertility levels in many Western societies have been associated with low gender equality, which arguably prevents some women from realizing their fertility plans as that would entail too high opportunity costs to their career, income, and other activities (Esping-Andersen, Boertien, Bonke, \& Gracia, 2013). However, the aggregate level connection between gender equality and fertility at the level of countries, regions and population groups remain relatively little researched and any evidence should be treated as tentative.

Many more studies addressed individual-level links between gender equality, fertility intentions and actual fertility behavior. The effect of gender equality on fertility intentions and behavior reveal inconclusive results, partly due to different concepts employed (Goldscheider, Oláh, \& Puur, 2010; Puur, Oláh, Tazi-Preve, \& Dorbritz, 2008; Westoff \& Higgins, 2009).

\footnotetext{
${ }^{6}$ This chapter refers to the statement 51 in the OECD strategy note.
} 
In general, two notions are distinguished: gender equality and gender equity.

Gender equality refers to the effective distribution (e.g. employment, wages, education, health). Gender equity captures fairness (or perceived fairness) and social justice (Fraser, 1994) (McDonald, 2000a, 2000b).

Association between gender equality and fertility (Neyer, Lappegard, \& Vignoli, 2013):

- need to account for perceived fairness of the distribution,

- need to distinguish between distribution of household and childcare work,

- need to look at men and women separately and

- need to distinguish parity.

Recent insights on the link between gender equality and fertility can be summarized as follows:

- Capacity to maintain a household (defined via own full-time employment) is essential for childless women and men in intending to have a child in the next 3 years.

- For childless couples, there is a positive effect of full-time employment on childbearing intentions. For parents, this effect disappears for women and remains positive for men.

- Gender-balanced division of household and childcare tends to support childbearing intentions of both women and men.

$\rightarrow$ There is a need to consider satisfaction together with the division of household work and care.

\section{Highly Educated Women and Female Scientists ${ }^{7}$}

\section{Key message:}

- Childlessness is exceptionally high among tertiary educated women and scientists

In Austria, but also in Western Germany and Switzerland, tertiary educated women have exceptionally high levels of childlessness (Figure 8). Fertility intentions of highly educated women and female scientists in Austria are in contrast to their realized family sizes (Figure 9) (Buber-Ennser, Panova, \& Dorbritz, 2013; Buber, Berghammer, \& Prskawetz, 2011).

\footnotetext{
${ }^{7}$ This chapter refers to the statements 51 and 66 in the OECD strategy note.
} 
Figure 8: Childlessness among tertiary educated women

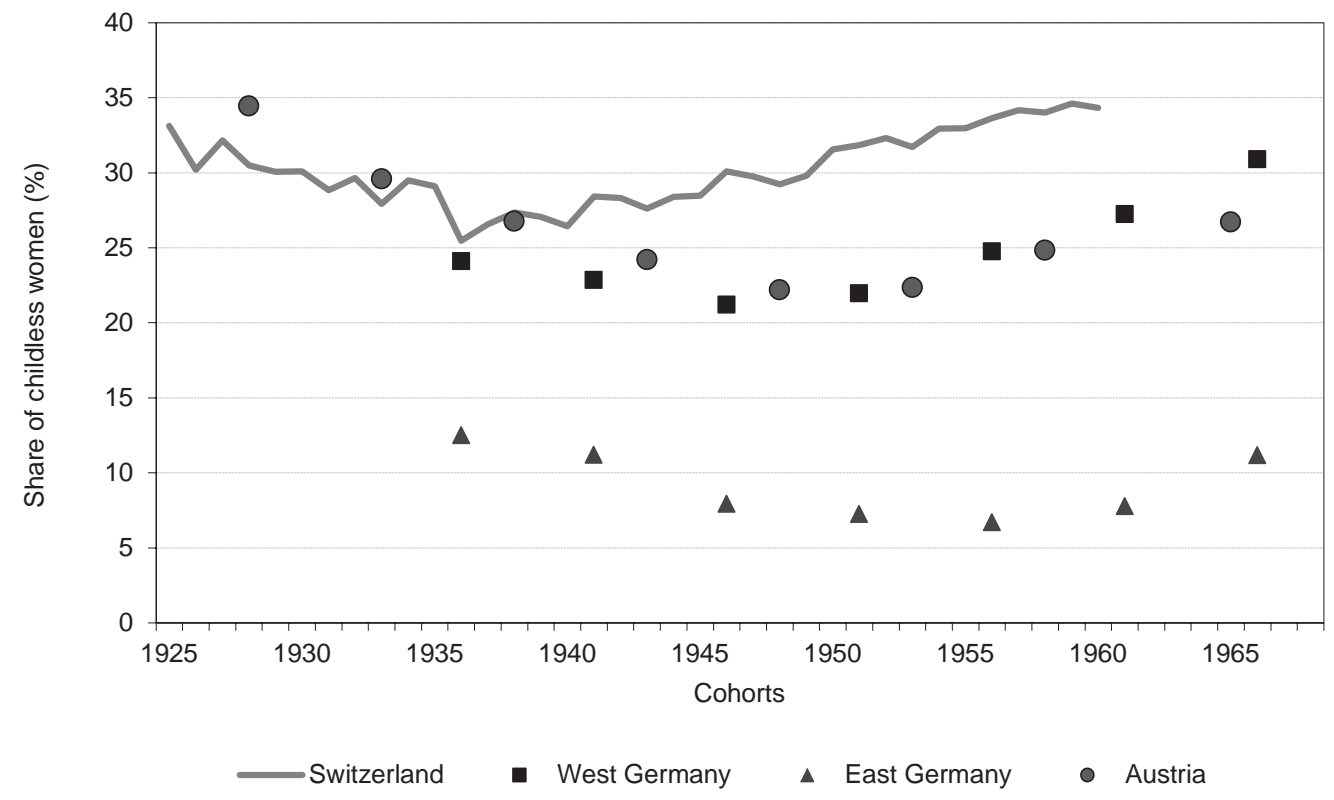

Source: Stock et al. (2012)

Figure 9: Ideal, intended, and realized number of children by educational level

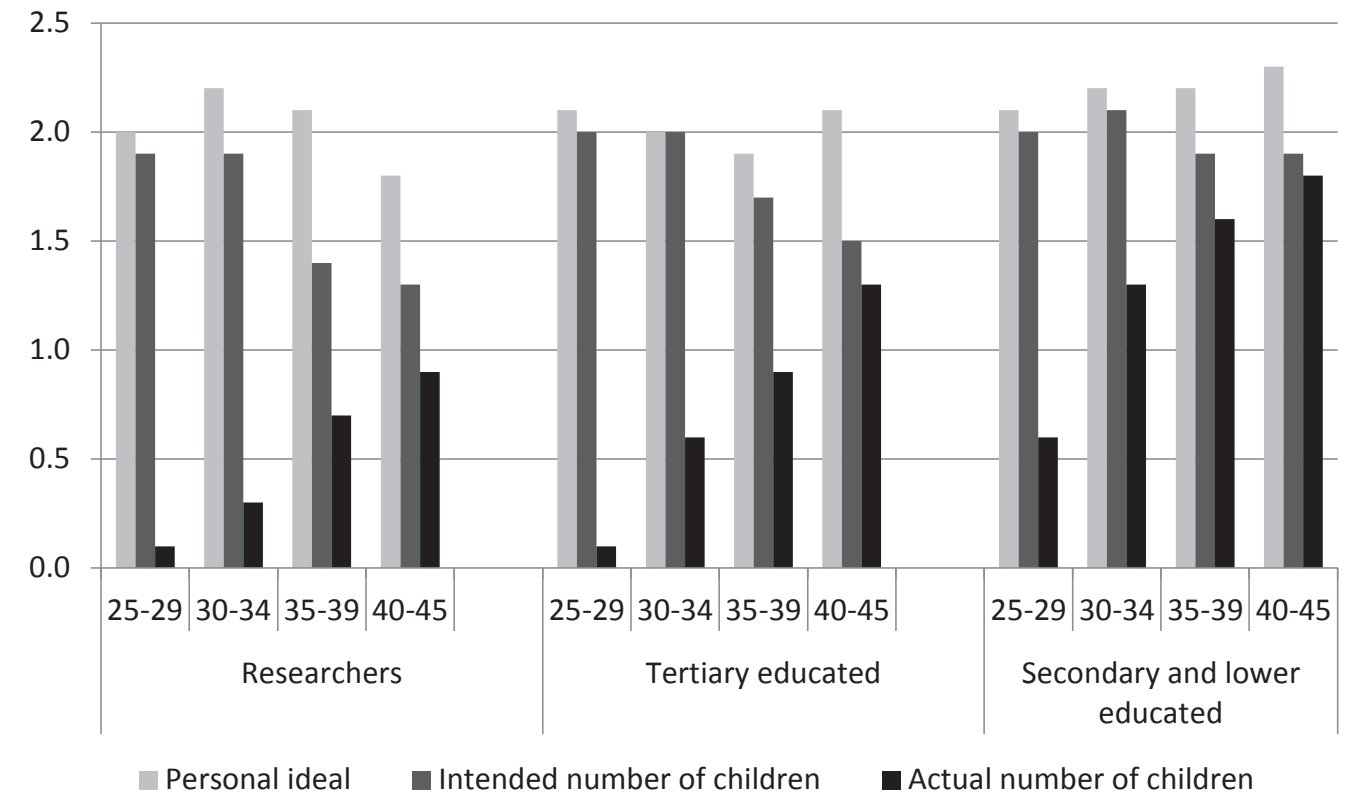

Source: Buber et al. (2011)

A study on fertility intentions of university graduates (Buber-Ennser et al., 2013) revealed that in Western Germany and Austria childless highly educated women are less likely to intend to have a child within the next three years. Moreover, gender differences are notable in these two countries, with women less often intending to have a child in the 
near future than men. Childbearing plans are most prominent among university graduates around the age of thirty. The degree of institutionalization, the duration of the relationship and the number of working hours are also associated with fertility intentions.

The German educational system in Germany and Austria, especially in academic professions, does not show much differentiation and access to professional life is generally defined by one's highest completed level of education. Other countries, in particular northern European and Anglo-Saxon ones, offer a variety of educational qualifications that can be acquired at various stages of life, thus allowing for flexible arrangement of life plans over the life course (Bundesministerium für Familie, Senioren, Frauen und Jugend BMFSFJ, 2006).

Childlessness among female researchers in Austria and Germany is very pronounced (above 40\%) (Buchholz, 2004; Fieder et al., 2005). Recent results indicate that the low level of realized fertility among the researchers is in sharp contrast to their personal ideals and intentions (Buber et al., 2011). For most researchers, children are part of their life concept, but they only manage to have about half of their personal ideal number. Regarding intended childlessness, data indicate that the great majority intends to have children in the short or long run. Personal and professional obstacles are associated with voluntary childlessness (Buber et al., 2011).

\section{The key obstacles identified for the female researchers were as follows:}

- time structure of work differs from that of most other occupations (tend to have long working hours; particularly in times of high demand, work spills into free time);

- contracts are often temporary causing uncertainty regarding future plans, job mobility (research abroad, conferences, guest lectures, further extended education)

- personal obstacles: higher share living in a "living-apart-together" relationship (separate flats and often separate place of residence of their partner), often linked to employment (different places of work)

\section{Distribution of Childcare Tasks and Fertility Intentions ${ }^{8}$}

\section{Key message:}

- It is not the actual distribution of household and childcare tasks, but rather the satisfaction with this division that pays an important role in both intending to have a child and in realizing these fertility intentions

Several analyses have been carried out at VID.

1995/96 data (Family and Fertility Survey (FFS)):

\footnotetext{
${ }^{8}$ This chapter refers to the statement 60 in the OECD strategy note.
} 
- Women with one child: sharing childcare duties among couples is a driving force behind plans for further childbearing, whereas the division of household tasks between men and women has no explanatory power.

- Satisfaction with the distribution of childcaring duties and household tasks had no effect on wanting a child within the next two years, and a minor effect on wanting a second child at all (Buber-Ennser, 2003).

2008/9 data (Generations and Gender Survey (GGS), wave 1):

- Men's participation in childrearing but also the satisfaction with the distribution of childcare between partners influence wanting a second child (Buber \& Neuwirth, 2009).

- Despite the unequal distribution of childcare tasks between partners, two out of three mothers were very satisfied with the distribution of childcare tasks with their partner (49\% of women ranked satisfaction with 10 out of 10 , further $16 \%$ with 9 out of 10). Fathers: satisfaction with the distribution was even higher, three out of four were very satisfied.

2012/13 data (Generations and Gender Survey (GGS), wave 2):

- Not only the intention to have a further child depends on the mothers' satisfaction with the division of childcare tasks, but also that satisfaction is crucial for realizing intentions (Buber-Ennser, Neuwirth, \& Testa, 2014a, 2014b).

- Mothers who were satisfied with the division in 2009 intended to have another child more often than less satisfied mothers. Satisfied mothers: six in ten wanted a second child. Less satisfied: one-third planned a second child.

- Realization of childbearing intentions: mothers not satisfied with arrangement realized intention less often than satisfied mothers (one-third versus two-thirds)

- Importance of women's satisfaction with the division of child care duties for any plans to have further children as well as for the realization of such plans in Austria (Figure 10).

- Distinction between household work (especially traditionally feminine chores) and child care tasks is important. Qualitatively different dimensions, childcare more than just an additional element of family work 
Figure 10: Realization of fertility plans within 4 years in Austria by mothers' satisfaction with distribution of childcare tasks

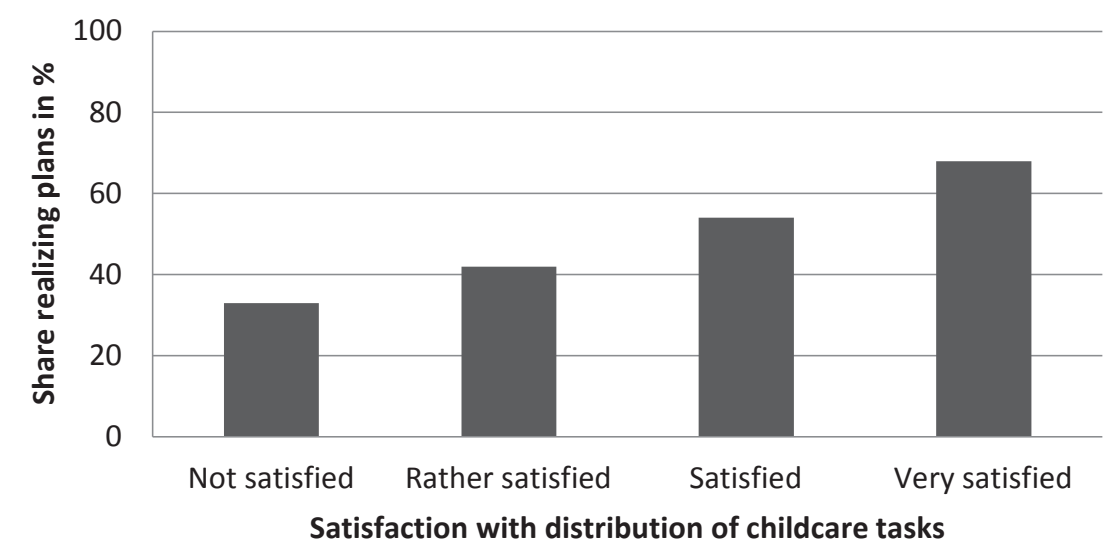

Source: Buber et al. (2014a)

\section{Men on Parental Leave in Austria ${ }^{9}$}

\section{Key message:}

- Relatively few fathers take parental leave in Austria, especially for a longer period, despite parental leave regulations providing an incentive for fathers to participate

2011: among all parents on parental leave, $8 \%$ were male.

- Fathers go on parental leave for a comparably short period, only $4 \%$ of all parental leave days have been contributed to fathers.

- The introduction of different parental-leave-options (shorter periods of leave, higher transfer payments) in 2008 induced a remarkable increase in the share of fathers on parental leave, but from an extremely low staring base (Reidl \& Schiffbänker, 2013).

2012: according to a newspaper report (Herrnböck, 2012), fathers' share on total leave taken was only $4.7 \%$, while $17 \%$ of all fathers took at least some leave, typically of a short duration of several months.

An international review (Moss, 2012) summarizes: Where leave is a family entitlement only, fathers' use is low (e.g. CZ, FI, Poland, AT). Where parental leave has both an individual entitlement element and is relatively well paid, fathers' use is higher (Nordic countries).

- Denmark (among parents of children born in 2005, 24\% of fathers took parental leave)

- Iceland (in 2008, 91\% fathers took a period of leave)

\footnotetext{
${ }^{9}$ This chapter refers to the statement 64 in the OECD strategy note.
} 
- Norway (in 2007, 70\% of fathers took more than 5 weeks)

- Sweden (1998: 89\% of fathers took parental leave; 2010: 44\% of parental leave benefit recipients).

A recent study reveals that in Austria, fathers' paternity leave often constitutes only an "excursion" into family life. Afterwards family and childcare responsibilities have to be "left behind" again. There is no support for involvement beyond the short leave period (Holzinger, Reidl, \& Schiffbänker, 2014).

Fathers' contribution to child care and domestic work

A recent study focused on the connection between fathers' participation in unpaid work and fertility in Europe and the US (Sullivan, Billari, \& Altintas, 2014). Increases are observed in the contribution of younger, more highly educated fathers to child care and core domestic work in very low-fertility in countries that have recently experienced upturn in fertility. Although causalities could not be studied, findings indicate a connection between fathers' increasing participation in unpaid work and fertility.

Impact of family policies on fertility

- Evidence from Norway shows that parental leave policy is the most influential policy instrument for second births, especially if parental leave is also taken by the father. The introduction of the childcare cash benefit is most influential for third births (Lappegard, 2010).

- Conclusion: Policies that promote paternal involvement in childcare and gender equality are positively associated with second births, while policies giving more general family support are positively associated with third births (Lappegard, 2010).

\section{Parental Leave Policies in Austria ${ }^{10}$}

\section{Key message:}

- Family policies in the $21^{\text {st }}$ century should take into account flexibility in time use across the life course

With regard to parental leave policies, a short and well-paid parental leave alternative of 12 $(+2)$ months was added to the existing schemes in 2010. Nevertheless, the longest version of $30(+6)$ months remains by far the most popular option. While claims to this longest version are very slowly declining, the shorter versions are arguably becoming more attractive (Rille-Pfeiffer \& Kapella, 2012). They are disproportionally used by mothers with a high income, and fathers engage most frequently in them.

A study on effects of changes in the duration of parental leave in Austria is worth mentioning (Lalive \& Zweimüller, 2009). It focused on mothers' higher-order fertility and

\footnotetext{
${ }^{10}$ This chapter refers to the statement 67 in the OECD strategy note.
} 
post-birth labour market careers. Analyses focuses on a major reform increasing the duration of parental leave from 1 year to 2 years in mid-1990.

The results reveal that mothers who give birth to their first child immediately after the reform have a slightly higher share of second children than pre-reform mothers. Mothers with entitlement to 2 years of parental leave have a 5 percentage points higher probability of getting an additional child within the following three years and a 4 percentage points higher probability persisting after 10 years since first birth.

This suggests that not only the timing but also the number of children was affected by the policy change, although another study by Št'astná and Sobotka (2009) found no permanent effect of changes in parental leave regulations on lifetime probability on having another child.

Lalive \& Zweimüller (2009) also found that extended parental leave significantly reduces return to work. However if employment and earnings decrease in the short run, they do not in the long run (Lalive \& Zweimüller, 2009).

Families need money, time and infrastructure (Stock et al., 2012). A large interdisciplinary project on families in Germany, Austria and Switzerland argues that for the well-being of (potential) parents and children family policy has to take into consideration the trias time-money-infrastructure. Over the different phases of the life course, families need different amounts of time to care for each other. Shared time needed for care cannot be planned in advance. A time-policy related to the life course has to take into account different time needs in different phases over the life course. Families must be sure that in specific phases of the life course there is enough time for care and for the needs of the family members, like around the birth of a child, school entry or school change of children, change of residency or in case of sickness of a child, a parent or a person caring for children (Stock et al., 2012).

Lalive and Zweimüller (2009) studied the effects of changes in the duration of parental leave in Austria. The focus is on higher-order fertility and labour market careers and the authors concentrate on a major parental leave reform in 1990, when duration increased from one to two years (for children born in July 1990 or later). It turned out that mothers who give birth to their first child immediately after the reform had more second children than pre-reform mothers. Extended parental leave significantly reduced returns to work (Figure 11), employment and earnings decreased in the short run but not in the long run (Figure 12). 
Figure 11: Return to work after parental leave

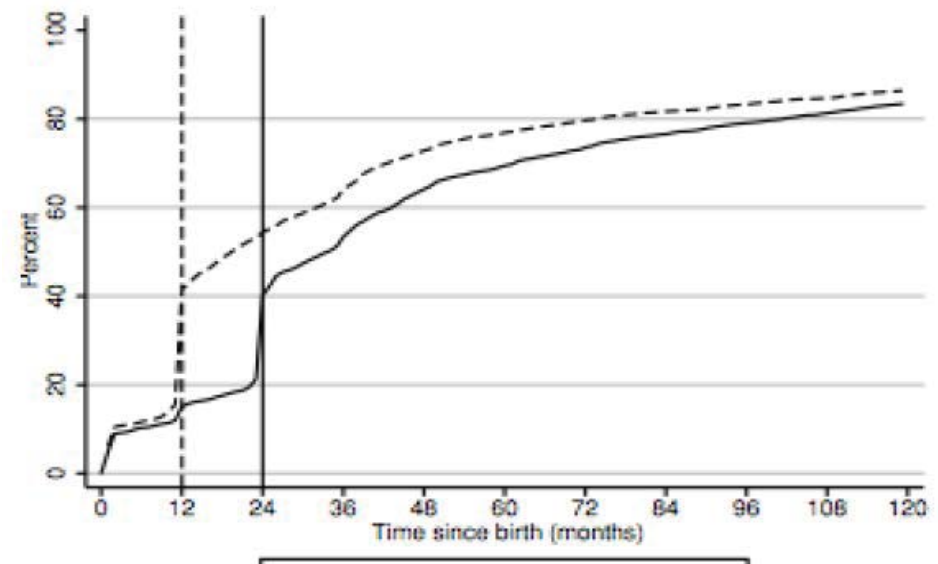

- - J-* June 1990 July 1990

Source: Lalive and Zweimüller (2009)

Figure 12: Earnings after parental leave

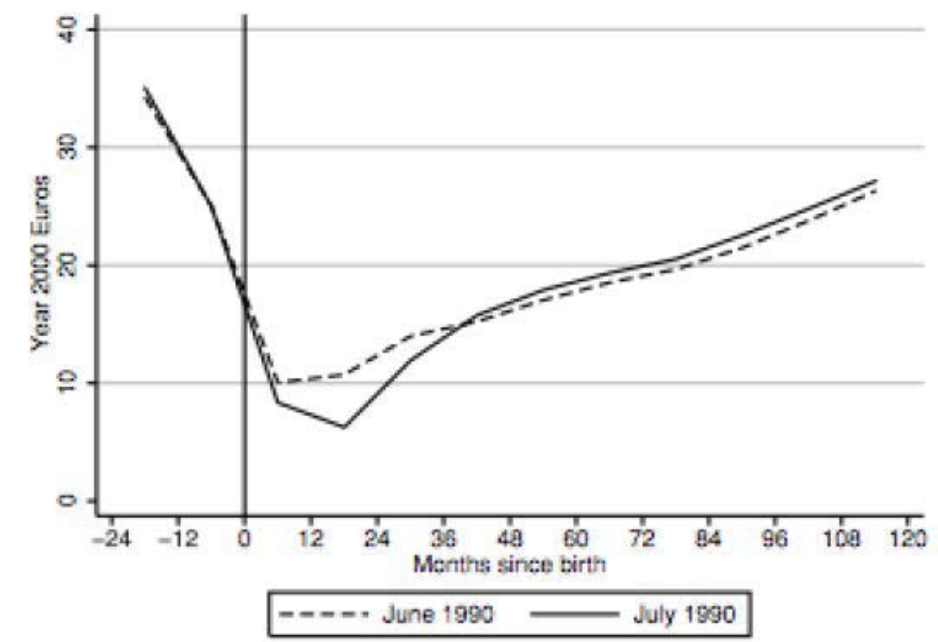

Source: Lalive and Zweimüller (2009)

\section{Cultural Norms Regarding Childcare ${ }^{11}$}

\section{Key message:}

- Cultural norms are important in the context of childcare services use

Apart from availability and affordability, cultural norms regarding childcare and maternal employment also influence actual use of childcare services. In a comparison between French and German women, Fagnani (2002) concluded that differences between state

${ }^{11}$ This chapter refers to the statement 68 in the OECD strategy note. 
policies should not be overestimated in explaining the persistent fertility gap between the two countries. She underlined the strong differences in women's attitudes towards childcare outside of the home. While childcare services seem to be generally accepted in France, the attitude in Western Germany is that children should not attend childcare facilities until they are at least two or even three years old (Fagnani, 2002). In Norway, where use of childcare facilities for children above one year is generally accepted, there seems to be an informal norm that children should not spend too many hours in childcare (Plantenga \& Remery, 2009). From the life-course perspective, Norwegian women perceive their labour market participation as a "natural" choice which is not in opposition to child raising (Lappegard, 2000, p. 16).

\section{Public Spending on Families}

\section{Key message:}

- Cash supports are comparably high, spending on services and tax measures low. This unique combination supports traditional gender roles

In Austria public spending on family benefits in cash was above OECD average in 2009 and amounted to $2.95 \%$ of the GDP (OECD, 2014). Cash supports were comparably high, whereas spending on services was low and tax breaks towards families were almost nonexisting (0.04\% of GDP) (Figure 13). This distribution of public spending on families reflects on the one hand the aim to economically support families, with a comparable long period of paid parental leave, which is taken mainly by mothers. On the other hand, spending on services has been comparably low, endorsing traditional family role models.

Figure 13: Public spending on families

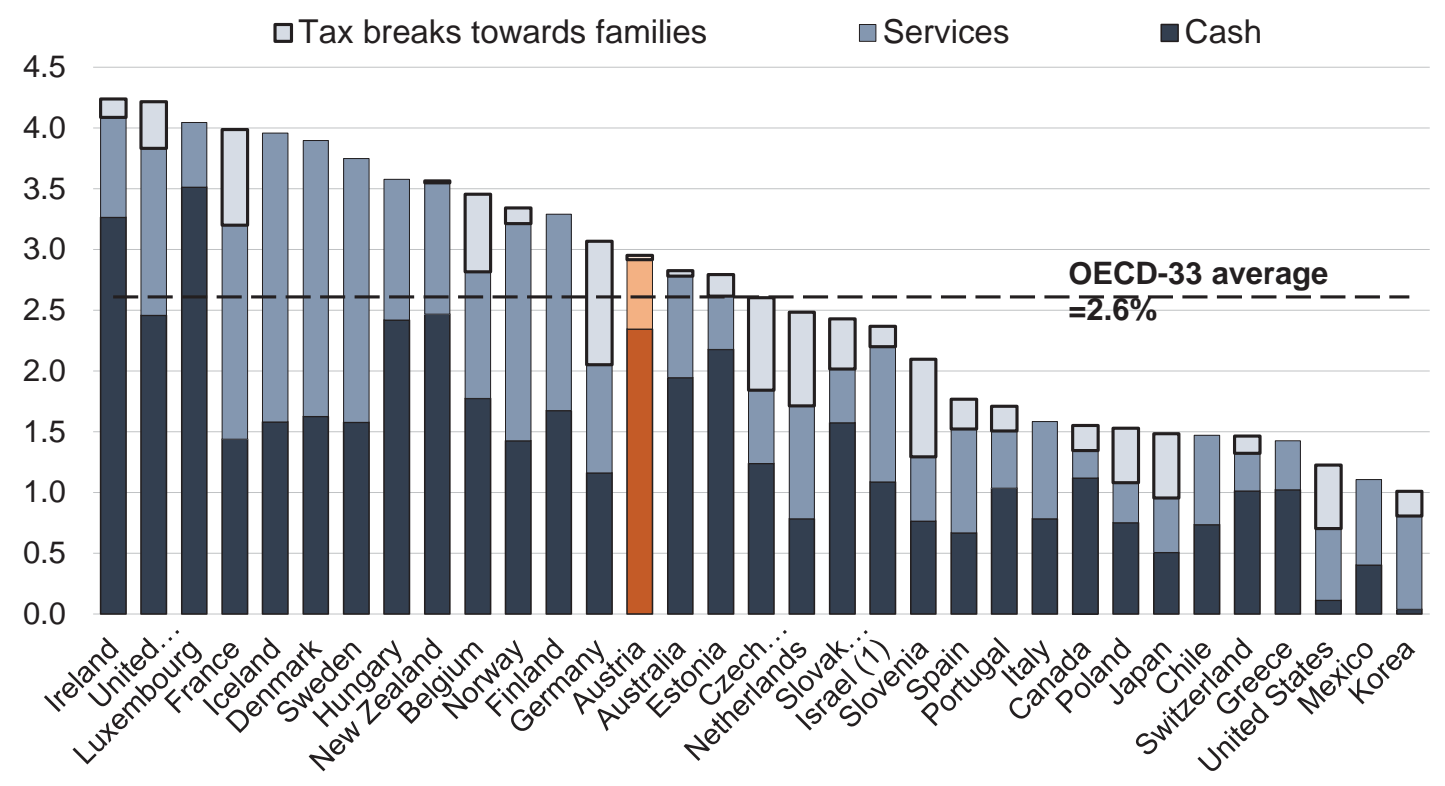

Source: OECD Family Database 


\section{Conclusion}

Austria can be characterised as a Western European country with low levels of fertility. A combination of mothers' part-time labour participation and fathers' full-time employment has emerged as a new dominant model of parents' labour participation across all education groups. Regarding attitudes towards employment of mothers with pre-school children, Austria holds a medium position, with large differences between women and men. Relatively few fathers take parental leave in Austria, especially for a longer period, despite parental leave regulations providing an incentive for fathers to participate. Nevertheless, Austrians are particularly aware of fathers' presence and active role in childrearing.

The provision of childcare facilities is crucial for mother's labour force participation and for reducing gender inequalities on the labour market. Enrolment in childcare services for children below age three remains comparatively low in Austria, but has been increasing rapidly after 2007, doubling in 2007-2013. To add, huge regional differences in enrolment and accessibility of full-day early childcare exist and constitute barriers to combine motherhood and (full-time) employment

Inequalities in the distribution of household tasks and childcare duties between women and men are large, but empirical evidence reveals that only if the actual gender differences are also perceived as gender inequalities (i.e., as being unfair or unjust), depressing effects on fertility may be expected. It is not the actual distribution of household and childcare tasks, but rather the satisfaction with this division that pays an important role in both intending to have a child and in realizing these fertility intentions. 


\section{References}

Berghammer, C. (2013). Keine Zeit für Kinder? Veränderungen in der Kinderbetreuungszeit von Eltern in Deutschland und Österreich. Zeitschrift für Soziologie, 42(1), 52-73.

Berghammer, C. (2014). The return of the male breadwinner model? Educational effects on parents' work arrangements in Austria, 1980-2009. Work, Employment and Society, 28(4), 611-623.

Blum, S., \& Kaindl, M. (2014). Bund-Länder-Programm zum Betreuungsausbau. Fallstudien zur Umsetzung in sechs österreichischen Städten. Forschungsbericht 14. Vienna: Austrian Institute for Family Studies.

BMFSFJ. (2006). Familie zwischen Flexibilität und Verlässlichkeit. Perspektiven für eine lebenslaufbezogene Familienpolitik. Siebter Familienbericht. Berlin: Bundesministerium für Familie, Senioren, Frauen und Jugend.

Buber-Ennser, I. (2003). The influence of the distribution of household and childrearing tasks between men and women on childbearing intentions in Austria. Vienna Yearbook of Population Research, 2013, 165-180.

Buber-Ennser, I., Neuwirth, N., \& Testa, M. R. (2014a). Division of child care tasks and realisation of childbearing intentions. In I. Buber-Ennser, N. Neuwirth \& M. R. Testa (Eds.), Families in Austria 2009-2013. Descriptive findings on partnership, fertility intentions, childbearing and childrearing (pp. 22). Vienna: Vienna Institute of Demography.

Buber-Ennser, I., Neuwirth, N., \& Testa, M. R. (2014b). Families in Austria 2009-2013. Descriptive findings on partnerships, fertility intentions, childbearing and childrearing. Vienna: Vienna Institute of Demography.

Buber-Ennser, I., \& Panova, R. (2014). Attitudes towards parental employment across Europe, in Australia and in Japan. VID Working Paper 5/2014, Vienna: Vienna Institute of Demography.

Buber-Ennser, I., Panova, R., \& Dorbritz, J. (2013). Fertility intentions of university graduates. Demográfia, 56(5), 5-34.

Buber, I., Berghammer, C., \& Prskawetz, A. (2011). Doing science forgoing children. VID Working Paper 1/2011, Vienna: Vienna Institute of Demography.

Buber, I., \& Neuwirth, N. (2009). Familienentwicklng in Österreich. Erste Ergebnisse des "Generations and Gender Survey (GGS)" 2008/09. Vienna: Vienna Institute of Demography.

Buchholz, L. (2004). Wissenschaftskarrieren an österreichischen Universitäten. Erfahrungen und Einstellungen von Professorinnen und Professoren [Scientific careers at Austrian universities. Experience and attitudes of male and female professors]. In E. Appelt (Ed.), Karriereschere. Geschlechterverhältnisse im österreichischen Wissenschaftsbetrieb [Career gap. Gender relations in the Austrian academia] (pp. 71-91). Vienna: LIT.

Dörfler, S., Blum, S., \& Kaindl, M. (2014). Europäische Kinderbetreuungskulturen im Vergleich. Jüngste Entwicklungen in der vorschulischen Betreuung in Deutschland, Frankreich, Österreich und Schweden. Vienna: Austrian Institute for Family Research, Working Paper 82.

Esping-Andersen, G., Boertien, D., Bonke, J., \& Gracia, P. (2013). Couple specialization in multiple equilibria. European Sociological Review, 29(6), 1280-1294. 
Fagnani, J. (2002). Why do French women have more children than German women? Family policies and attitudes towards child care outside the home. Community, Work \& Family, 5(1), 103-119.

Fieder, M., Huber, S., Bookstein, F. L., Iber, K., Schäfer, K., Winckler, G., \& Wallner, B. (2005). Status and reproduction in humans: New evidence for the validity of evolutionary explanations on basis of a University sample. Ethology, 111, 940-950.

Fraser, N. (1994). After the family wage: Gender equity and the welfare state. Political Theory, 22(4), 591-618.

Goldscheider, F., Oláh, L. S., \& Puur, A. (2010). Reconciling studies of men’s gender attitudes and fertility: Response to Westoff and Higgins. Demographic Research, 22(8), 189-198.

Herrnböck, J. (2012, 20. November 2012). Väterkarenz: Streit über Zahlen [Paternal leave: a fight over the numbers], Der Standard. Retrieved from http://derstandard.at/1353206775448/Papamonat-Streit-ueber-Zahlen

Holzinger, F., Reidl, S., \& Schiffbänker, H. (2014). Vater werden ist nicht schwer, Vater sein hingegen sehr ...?: Unterschiedliche Motive, Erfahrungen und Vereinbarkeitspraktiken von Vätern in Karenz. WP 76, Vienna: Johanneum Research.

Klapfer, K. (2010). Erwerbstätigkeit von Müttern und Vätern. In Bundeskanzleramt Österreich (Ed.), Frauenbericht 2010 [Report on women 2010] (pp. 168-174). Vienna: Federal Ministry for Women and Civil Service.

Konietzka, D., \& Kreyenfeld, M. (2010). The growing educational divide in mothers' employment: an investigation based on the German micro-censuses 1976 - 2004. Work, Employment \& Society, 24(2), 260-278.

Lalive, R., \& Zweimüller, J. (2009). How does parental leave affect fertility and return to work? Evidence from two natural experiments. The Quarterly Journal of Economics, 124(3), 1363-1402.

Lappegard, T. (2000). New fertility trend in Norway. Demographic Research, 2(3), 1-23.

Lappegard, T. (2010). Family policies and fertility in Norway. European Journal of Population, 26, 99-116.

McDonald, P. (2000a). Gender equity in theories of fertility transition. Population and Development Review, 26(3), 427-439.

McDonald, P. (2000b). Gender equity, social institutions and the future of fertility. Journal of Population Research, 17(1), 1-16.

Moss, P. (Ed.). (2012). International review of leave policies and related research 2012. London: Institute of education, University of London.

Neyer, G., Lappegard, T., \& Vignoli, D. (2013). Gender equality and fertility: Which equality matters? European Journal of Population, 29(3), 245-272.

Plantenga, J., \& Remery, C. (2009). The provision of childcare services. A comparative review of 30 European countries. Luxembourg: Publications Office of the European Union.

Puur, A., Oláh, L. S., Tazi-Preve, M. I., \& Dorbritz, J. (2008). Men's childbearing desires and views of the male role in Europe at the dawn of the 21st century. Demographic Research, 19(56), 1883-1912.

Reidl, S., \& Schiffbänker, H. (2013). Karenzväter in Zahlen. Ergebnisse einer Analyse von Daten des Hauptverbands der Sozialversicherungsträger. Vienna: Johanneum Research. 
Rille-Pfeiffer, C., \& Kapella, O. (2012). Kinderbetreuungsgeld. Evaluierung einer familienpolitischen Maßnahme. Innsbruck: Austrian Institute for Family Research, Schriftenreihe Band 15.

Št’astná, A., \& Sobotka, T. (2009). Changing parental leave and shifts in second and thirdbirth rates in Austria. VID Working Paper 7/2009, Vienna: Vienna Insitute of Demography.

Stock, G., Bertram, H., Fürnkranz-Prskawetz, A., Holzgreve, W., Kohli, M., \& Staudinger, U. M. (Eds.). (2012). Zukunft mit Kindern Fertilität und gesellschaftliche Entwicklung in Deutschland, Österreich und der Schweiz. Frankfurt/Main, New York: Campus.

Sullivan, O., Billari, F. C., \& Altintas, E. (2014). Fathers' changing contributions to child care and domestic work in very low-fertility countries: The effect of education. Journal of Family Issues, 35(8), 1048-1065.

Wernhart, G., \& Neuwirth, N. (2007). Geschlechterrollenwandel und Familienwerte (1988-2002). Österreich im europäischen Vergleich. Ergebnisse auf Basis des ISSP 1998, 2002. ÖIF Working Paper 54, Vienna: Austrian Institute for Family Research.

Westoff, C. F., \& Higgins, J. (2009). Relationships between men's gender attitudes and fertility: Response to Puur et al.'s "Men's childbearing desires and views of the male role in Europe at the dawn of the 21st century", Demographic Research 19: 1883-1912. Demographic Research, 21(3), 65-74. 


\section{VIENNA INSTITUTE OF DEMOGRAPHY}

\section{Working Papers}

Buber-Ennser, Isabella and Ralina Panova, Attitudes towards Parental Employment across Europe, in Australia and in Japan, VID Working Paper 5/2014.

Kumar, Abhishek, Valeria Bordone and Raya Muttarak, Influence of Older Generation's Fertility Behaviours on Daughter's Desired Family Size in Bihar, India, VID Working Paper 4/2014.

Sobotka, Tomáš and Éva Beaujouan, Two is Best? The Persistence of a Two-child Family Ideal in Europe, VID Working Paper 3/2014.

Sander, Nikola, Guy J. Abel, Ramon Bauer and Johannes Schmidt, Visualising Migration Flow Data with Circular Plots, VID Working Paper 2/2014.

Barakat, Bilal, Revisiting the History of Fertility Concentration and its Measurement, VID Working Paper 1/2014.

Buber-Ennser, Isabella, Attrition in the Austrian Generations and Gender Survey, VID Working Paper 10/2013.

De Rose, Alessandra and Maria Rita Testa, Climate Change and Reproductive Intentions in Europe, VID Working Paper 09/2013.

Di Giulio, Paola, Thomas Fent, Dimiter Philipov, Jana Vobecká and Maria WinklerDworak, State of the Art: A Family-Related Foresight Approach, VID Working Paper 08/2013.

Sander, Nikola, Guy J. Abel and Fernando Riosmena, The Future of International Migration: Developing Expert-Based Assumptions for Global Population Projections, VID Working Paper 07/2013.

Caselli, Graziella, Sven Drefahl, Marc Luy and Christian Wegner-Siegmundt, Future Mortality in Low-Mortality Countries, VID Working Paper 06/2013.

Basten, Stuart, Tomáš Sobotka and Kryštof Zeman, Future Fertility in Low Fertility Countries, VID Working Paper 05/2013.

Sharygin, Ethan, The Carbon Cost of an Educated Future: A Consumer Lifestyle Approach, VID Working Paper 04/2013.

The Vienna Institute of Demography Working Paper Series receives only limited review. Views or opinions expressed herein are entirely those of the authors. 